\title{
Status Perempuan Dalam Lingkungan Masyarakat
}

\author{
Sriweni Antika Masarrang \\ sriweniantikamasarrang@gmail.com
}

\begin{abstract}
This paper describes the status of women in society. The status of women who are considered lower than men is due to differences. But basically women can also play a role in society. Women also have an influence on the community environment.

Abstrak

Dalam tulisan ini menjelaskan tentang status perempuan dalam lingkungan masyarakat. Status perempuan yang dianggap rendah dari laki-laki dikarenakan adanya perbedaan. Tetapi pada dasarnya perempuan juga bisa berperan dalam lingkungan masyarakat. Perempuan juga memiliki pengaruh terhadap lingkungan masyarakat.
\end{abstract}

\section{A. Pendahuluan}

Status perempuan dalam masyarakat pada saat ini hampir sama dengan status lakilaki. Perempuan yang sudah tidak memiliki batasan dalam lingkungan masyarakat, tentunya sudah bisa menjadi pemimpin dalam memimpin suatu masyarakat. Dalam hal ini dapat dikatakan bahwa perempuan sudah mendapat penerimaan dalam lingkungan masyarakat. Bahkan perempuan pada saat ini dalam lingkungan keluarga, sudah bisa memegang dua peran sekaligus dalam sebuah keluarga. Bisa menjadi seorang ibu rumah tangga dan bahkan ada juga yang menjadi kepala rumah tangga.

Perempuan yang dahulunya dianggap remeh, bahkan dianggap bahwa tidak bisa melakukan apa-apa selain menjadi ibu rumah tangga. Bahkan sebuah pandangan yang tidak adil terhadap perempuan itu muncul dikarenakan perempuan yang dipandang irasional, emosional dan lemah. ${ }^{1}$ Sehingga peran-peran perempuan pun dibatasi dan dianggap tidak penting. Tetapi sekarang perempuan sudah tidak bisa dianggap seperti itu lagi karena pada saat ini, sudah banyak perempuan yang dikenal sebagai inspirasi dalam membangun kehidupan masyarakat. Perempuan juga sudah memiliki peran penting dalam masyarakat. Dalam hal ini dalam lingkungan masyarakat tentunya peran perempuan juga sangat dibutuhkan.

\section{Tujuan dan manfaat}

\footnotetext{
${ }^{1}$ Dimyati Huda, Rethinking Peran Perempuan dan Keadilan Gender (Bandung: CV CENDEKIA PRESS, 2020), HIm 8.
} 
Tujuan dari penulisan makalah ini ialah, penulis ingin menjelaskan bagaimana status dan peran perempuan dalam suatu lingkungan masyarakat. Manfaat dari tulisan ini, agar pembaca bisa mengetahui status dan peran perempuan dalam lingkungan masyarakat.

\section{B. Pembahasan}

\section{Status dan peran perempuan}

Dalam kehidupan ini, tentunya kita mengetahui bahwa perempuan dan laki-laki tentunya dua manusia yang sangat memiliki perbedaan. Secara biologis, perempuan dan laki-laki tidak sama, dimana masing-masing jenis kelamin yang dimiliki masing-masing memiliki keterbatasan dan kelebihan yang berbedah. ${ }^{2}$ Laki-laki dan perempuan diciptakan dengan masing-masing fungsi baik secara fisik maupun secara psikisnya. Perempuan yang bisa melahirkan anak, tentunya dia yang akan merawat dan memberikan kasih saya terhadap anak yang dilahirkanya. Itu merupakan salah satu fungi nyata perempuan dalam kehidupan masyarakat. Dan laki-laki yang memiliki fisik yang kuat bertanggung jawab dalam mencari nafkah. ${ }^{3}$ Dalam artian bahwa laki-laki melakukan sebuah pekerjaan yang tidak bisa dilakukan oleh perempuan Karena perbedaan kekuatan yang dimiliki, dan pekerjaan yang dilakukan adalah untuk memenuhi kebutuhan keluarga. Perbedaan yang ada tentunnya berpengaruh, dan menumbuhkan pembagian pekerjaan. Padahal kita tau bahwa fungsi adalah sesuatu kemampuan yang ada dalam diri manusia dan sudah melekat yang tidak bisa berubah dan tidak sama bagi setiap manusia. Jelas berbeda dengan pembagian kerja, dimana keterampilan yang dimiliki oleh individu dan tergantung pada kerja sama yang dilakukan pelakunya, itu merupakan pembagian pekerjaan.

Situasi pembangian yang terjadi seperti itu, dengan menanamkan bahwa perempuan yang hanya bisa bekerja di rumah, dan laki-laki yang bisa melakukan pekerjaan yang tidak bisa dilakukan oleh perempuan, hal itu menanamkan pengetahuan dalam masyarakat bahwa wanita tidak bisa melakukan apa-apa kecuali di rumah. Seperti didalam istilah klasik mengatakan bahwa tugas perempuan tidak boleh lebih dari sekedar di dapur, sumur, kasur. ${ }^{4}$ Memberikan pemahaman bahwa perempuan tidak boleh menyuarakan hak-haknya. Perempuan yang dianggap lemah dan laki-laki dianggap kuat

\footnotetext{
${ }^{2}$ Gandhi Lapian, Disiplin Hukum yang Mewujudkan Kesetaraan dan Keadilan Gender (Jakarta: Yayasan Pustaka Obor Indonesia, 2012), ix.

${ }^{3}$ Puji Lestari, "Peranan dan status perempuan dalam sistem sosial” Dimensia: Jurnal kajian sosial 5, No 1 (Maret 2011): 45-60, https://doi.org/10.21831/dimensia.v5i1.3439

${ }^{4}$ Alfian Rokhnabsyah, Pengantar Gender dan Feminisme (Yogyakarta: Garudhawaca, 2016 ),13.
} 
dan memiliki kelebihan. ${ }^{5}$ Hal ini yang pernah terjadi dalam lingkungan masyarakat tradisional. Perempuan yang pernah dianggap memiliki status yang rendah dari laki-laki. Tetapi hal itu berubah seiring berjalanya waktu, dengan adanya pengetahuan dan pendidikan yang cukup tinggi itu bisa mengubah keadaan. Bukan berarti perempuan dalam keluarga akan menjadi suami. Tetapi artinya bahwa perempuan juga bisa berperan di luar lingkungan keluarga. Bahkan Perempuan bisa menjadi seorang pemimpin.

\section{Lingkungan masyarakat}

Lingkungan masyarakat adalah lembaga ketiga setelah lingkungan keluarga dan sekolah. Masyarakat adalah suatu bentuk tata kehidupan sosial dan tata-nilai dan tatabudaya sendiri. dalam artian bahwa masyarakat merupakan tempat kehidupan manusia yang memiliki perbedaan baik suku, agama, kegiatan-kerja, tingkat pendidikan,tingkat sosial ekonomi dan sebagainya. ${ }^{6}$ Lingkungan masyarakat adalah adanya interaksi yang dilakukan oleh sekolompok orang dengan masyarakat lainya, dimana mereka saling mempengaruhi satu dengan yang lain.

Masyarakat yang merupakan kumpulan induvidu yang hidup bersama dimana terikat oleh satu satuan adat, ritus atau hukum khas. ${ }^{7}$ Perempuan yang merupakan bagian dari masyarakat tentunya memiliki ciri khas yang tidak terdpat pada laki-laki yaitu kemampuan dalam melahirkan suatu penerus generasi. Masyarakat yang merupakan tempat terjadi interaksi sosial. Banyak perbedaan-perbedaan yang ada. Perbedaan tersebut yang dapat memberikan batasan bagi individu. Sama seperti pembatasan peran yang terjadi pada perempuan. Tetapi karena adanya pemahaman yang di miliki dan pendidikan yang tinggi dalam masyarakat yang mampu mengubah adanya pembatasan peran dalam masyarakat.

\section{Status dan peran perempuan dalam lingkungan masyarakat}

Peran dan status yang dimiliki oleh perempuan, dapat dilihat dari sejauh mana perempuan terlibat dalam berbagai aspek yang ada dalam lingkungan masyarakat. Status dan perempuan yang awalnya dibatasi, seperti perempuan yang diketahui hanya memiliki peran dalam keluarga, sekarang sudah memiliki peran bahkan juga berpengaruh pada

\footnotetext{
${ }^{5}$ Rannu sanderan, “Jabatan gerejawi dan peran perempuandalam pelayanan gereja”.

${ }^{6}$ Tim Dosen FIP-IKIP Malang, Pengantar Dasar-dasar Kependidikan, Usaha Nasional, Surabaya, 1981,

${ }^{7}$ Dimyati Huda, Rethinking Peran Perempuan dan Keadilan Gender (Bandung: CV CENDEKIA PRESS,
} hal 15. 2020), HIm 41. 
lingkungan masyarakat. Perempuan yang juga merupakan bagian dari masyarakat mempunyai hak dan kewajiban yang sama dengan pria dalam mensejahterakan kehidupan masyarakat. Maka kedudukanya dalam masyarakat dan peranya dalam pembangunnan perlu ditingkatkan serta diarahkan sehingga dapat meningkatkan partisipasinya dalam bagi masyarakat sesuai dengan kodrat, harkat dan martabatnya sebagai perempuan.

Seiring berjalan waktu perempuan yang dianggap lemah dan diremehkan mulai bangkit dari keterpurukan yang dirasakan. Mulai membuktikan sebuah keberhasilan bahwa keberadaan mereka layak untuk diterima dan diperhitungkan dalam lingkungan masyarakat. Salah satu contoh, peran perempuan dalam upaya peningkatan perekonomian dan kesejahteraan masyarakat. Bukan Cuma itu, keterlibatan perempuan di bidang-bidang lainya juga sudah banyak dilakukan. Bahkan ada beberapa perempuan yang menjadi perempuan inspirasi yang memberikan pengaruh dalam lingkungan masyarakat.

\section{Kesimpulan dan saran}

Perempuan dalam suatu lingkungan masyarakat, tentunya memiliki tempat yang sama dengan laki-laki. Perempuan seiring waktu akan bangkit dan akan menunjukkan sebuah keberhasilan. Peran dan status perempuan dipandang dari sejauh mana keterlibatanya dalam suatu aspek di dalam masyarakat.

Kedudukan perempuan tidaklah berbeda dengan laki-laki, meskipun pada awalnya dalam sejarah kehidupan perempuan dianggap rendah dari laki-laki. Tetapi pada masa sekarang kedudukan perempuan tidak bisa diremehkan lagi. Bahkan perempuan sudah bisa menjadi seorang pemimpin dalam suatu masyarakat. 


\section{Kepustakaan}

Huda, Dimyati. Rethinking Peran Perempuan dan Keadilan Gender. Bandung: CV CENDEKIA PRESS, 2020, 8.

Lapian,Gandhi. Disiplin Hukum yang Mewujudkan Kesetaraan dan Keadilan Gender. Jakarta: Yayasan Pustaka Obor Indonesia, 2012, ix.

Lestari,Puji. "Peranan dan status perempuan dalam sistem sosial" Dimensia: Jurnal kajian sosial 5, No 1 (Maret 2011): 45-60, https://doi.org/10.21831/dimensia.v5i1.3439

Rokhnabsyah, Alfian. Pengantar Gender dan Feminisme. Yogyakarta: Garudhawaca, 2016, 13.

sanderan, Rannu. "Jabatan gerejawi dan peran perempuan dalam pelayanan gereja" https://doi.org/index.php/jireh/article/view/39/36 [ accessed 1 Desember 2021]

Tim Dosen FIP-IKIP Malang, Pengantar Dasar-dasar Kependidikan, Usaha Nasional, Surabaya, 1981, 15. 